\title{
Extractive Distillation with Ionic Liquids To Separate Benzene, Toluene, and Xylene from Pyrolysis Gasoline: Process Design and Techno-Economic Comparison with the Morphylane Process
}

\author{
Miguel Ayuso, Pablo Navarro,* Cristian Moya, Daniel Moreno, José Palomar, Julián García, \\ and Francisco Rodríguez
}

Cite This: Ind. Eng. Chem. Res. 2022, 61, 2511-2523

Read Online

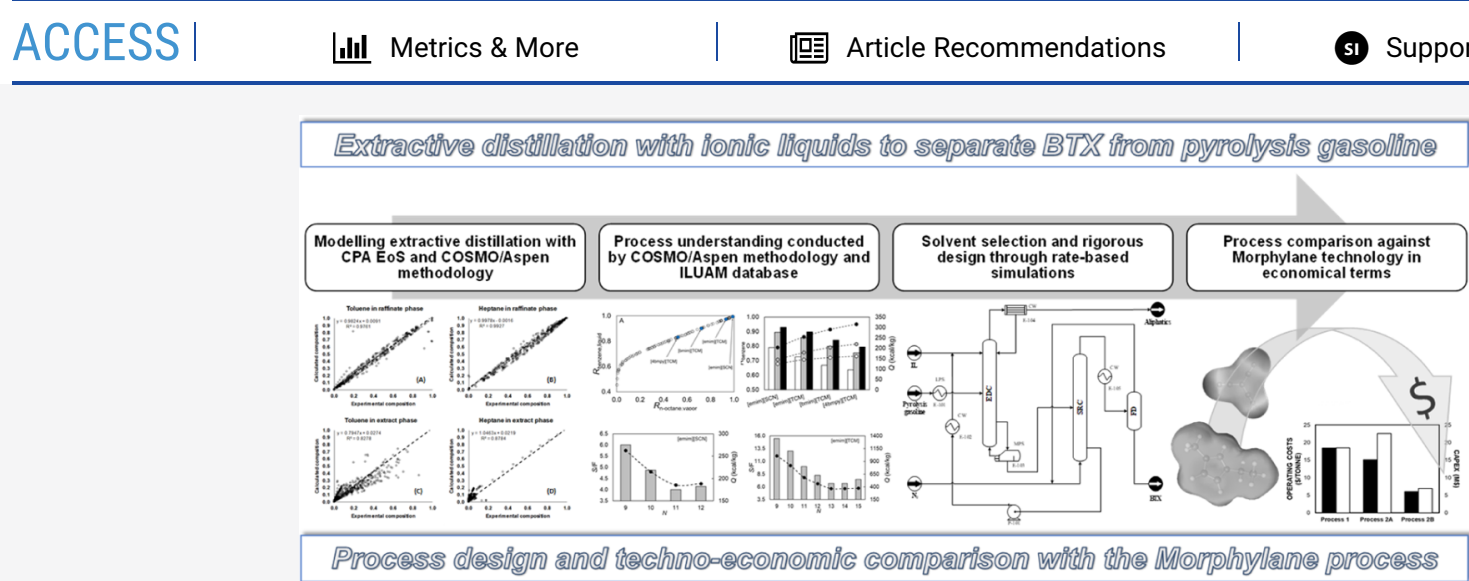

ABSTRACT: Aromatic/aliphatic separation stands as a challenge for both industry and academia. More and more efforts are being made to improve energy-demanding technologies based on liquid-liquid extraction or extractive distillation processes. Recently, ionic liquid-based technologies devoted to separating benzene, toluene, and xylene from pyrolysis gasoline have been evaluated, and extractive distillation showed more potential than liquid-liquid extraction in terms of separation performance and global energy requirements. In this work, extractive distillation with ionic liquids is completely evaluated from solvent selection to rate-based process design and compared with the Morphylane benchmark process. The ILUAM database is explored through a validated COSMO/Aspen methodology to understand the impact of the ionic liquid nature on the extractive distillation operation. A parametric study focused on the extractive distillation column (EDC) is conducted for preliminary set initial guesses to design task. The final issue is centered on rigorously designing the ionic liquid-based and Morphylane processes at commercial specifications. Two different ionic liquid-based process configurations are evaluated based on the opportunities that the use of ionic liquids enables. The new process configuration working with [emim] [TCM] reduces the energy costs and capital expenditures associated with the Morphylane process by 67 and 63\%, respectively, along with a reduction in the solvent costs, confirming it as a cleaner alternative. In addition, a parametrization of the Cubic Plus Association equation of state (CPA EoS) obtained from the regression of experimental vapor-liquid-liquid equilibrium data is also used to simulate the EDC in equilibrium and rate-based mode. Both models provide similar results, confirming the ability of the conductor-like screening model-segment activity coefficient model as an a priori tool and the reliability of the CPA EoS as a regressive alternative to describe these kinds of complex multicomponent systems.

\section{INTRODUCTION}

Petroleum refining gives rise to mixtures where aromatic and nonaromatic hydrocarbons coexist. ${ }^{1}$ Given the importance of aromatic hydrocarbons in the petrochemical industry, obtaining these compounds from refinery streams is crucial. Among the most relevant aromatic compounds are those known as the benzene, toluene, and xylene (BTX) fraction. In Europe, the BTX fraction is almost completely obtained from pyrolysis gasoline. ${ }^{2}$ This source presents $66 \mathrm{wt} \%$ of aromatic content, the rest being $\mathrm{C}_{6}-\mathrm{C}_{8}$ aliphatics. The main challenge to obtain the BTX fraction is their close boiling points to the nonaromatic compounds and the presence of azeotropes. Therefore, conventional distillation is unfeasible to achieve this purpose. Currently, the benchmark industrial processes to obtain BTX from refinery streams are the sulfolane and Morphylane processes. However, the great energy consumption involved in

Received: November 4, 2021

Revised: December 28, 2021

Accepted: January 24, 2022

Published: February 2, 2022 
these processes, together with the ever-increased environmental constraints, makes mandatory an update of these technologies leading to cleaner productions.

One of the most promising alternatives to the aforementioned processes involves the replacement of conventional organic solvents by ionic liquids. ${ }^{3,4}$ Ionic liquids are molten salts that present high thermal stability and negligible vapor pressure, so they do not produce atmospheric pollution. Furthermore, the possibility of combining a vast number of different anions and cations allows synthesizing ionic liquids with 'designed' extractive and thermophysical properties. Even mixtures of ionic liquids can also be obtained by simply mixing two of them, resulting in new solvents with intermediate properties. ${ }^{5,6}$ Such characteristics have promoted the interest in the application of ionic liquids in different industrial processes. ${ }^{7-12}$ This fact can be because the first ionic liquid-based processes at an industrial scale have already been implanted in different parts of the world. ${ }^{13-15}$

Specifically for the separation of aromatics from refinery streams, ionic liquids have been mainly tested as mass agents in liquid-liquid extraction. ${ }^{6,16-21}$ However, a complete dearomatization of gasoline was not possible through this technology, and extractive distillation was postulated as an alternative. Indeed, its suitability for the separation of BTX from aliphatics has been recently studied, overcoming the limitations regarding liquid-liquid extraction and improving energy expenses. ${ }^{22,23}$

Our research group developed a series of studies evaluating the feasibility of several ionic liquids as mass agents in the extractive distillation of different mixtures \{aliphatic + aromatic . First, an experimental screening of 10 ionic liquids was made to probe the influence of their extractive properties (aromatic selectivity and distribution ratio) on the $n$-heptane/ toluene relative volatility provided by each one. It was found that selectivity plays a dominant role in maximizing the aliphatic/ aromatic relative volatility, but an eye must also be kept on the distribution ratio to avoid two liquid phases in equilibrium. ${ }^{24-26}$ Tricyanomethanide-based ionic liquids, which have balanced extractive properties, turned out as the best mass agents. ${ }^{27}$ Then, the vapor-liquid and vapor-liquid-liquid equilibria (VLE/ VLLE) of several binary \{aliphatic or aromatic + ionic liquid\} and ternary systems $\{$ aliphatic + aromatic + ionic liquid $\}$ were determined in a wide range of temperatures and solvent-to-feed (S/F) ratios. Finally, all these data were modeled with the Cubic Plus Association equation of state (CPA EoS). ${ }^{28-30}$

In this work, a COSMO/Aspen Plus methodology developed in previous papers ${ }^{22,31}$ has also been validated here for massive VLE and LLE data found in the literature. The COSMO/Aspen methodology combines COSMO models and Aspen Plus simulator software to deal with COSMO predictions at the process scale. The so-called COSMO/Aspen methodology is related to the component definition as pseudocomponents in Aspen Plus by implementing their sigma profile and COSMO volume calculated by the conductor-like screening model for real solvent (COSMO-RS) model at COSMOtherm software to use conductor-like screening model-segment activity coefficient (COSMO-SAC) in Aspen Plus as explained for ionic liquids elsewhere. ${ }^{32}$ In this work, this approach has been used to simulate the extractive distillation of BTX from pyrolysis gasoline using ionic liquids. First, a preliminary screening of more than 100 ionic liquids (ILUAM database ${ }^{32}$ ) was conducted to check their performance as mass agents in the separation of binary mixtures $\{n$-octane + benzene $\}$ (key components of pyrolysis gasoline). Four ionic liquids, namely 1- ethyl-3-methylimidazolium thiocyanate ([emim $][\mathrm{SCN}])$, 1ethyl-3methylimidazolium tricyanomethanide ([emim][TCM]), 1-butyl-3methylimidazolium tricyanomethanide ([bmim $][\mathrm{TCM}]$ ), and 4-butyl-1-methylpyridinium tricyanomethanide $([4 \mathrm{bmpy}][\mathrm{TCM}])$, were selected to better understand the influence of the ionic liquid nature on the extractive distillation performance. Second, the whole extractive distillation process, including the recovery of the ionic liquid via nitrogen stripping, was simulated in equilibrium mode with $[\mathrm{emim}][\mathrm{TCM}]$ and $[\mathrm{emim}][\mathrm{SCN}]$. Third, [emim $][\mathrm{TCM}]$ was chosen to rigorously simulate the extractive distillation process in rate-based mode and compare its performance with $N$ formylmorpholine (NFM). The conventional NFM process, called the Morphylane process (Process 1), needs a predistillation column to remove the $\mathrm{C}_{8+}$ fraction from pyrolysis gasoline. ${ }^{33}$ However, as it was checked in a prior publication, ${ }^{22}$ as long as the pyrolysis gasoline is preheated up to its bubble point, $[\mathrm{emim}][\mathrm{TCM}]$ can separate the whole BTX fraction directly from pyrolysis gasoline without the necessity of the predistillation column. Therefore, two process configurations were simulated with $[\mathrm{emim}][\mathrm{TCM}]$ : one keeping the predistillation column as in the conventional Morphylane process (Process 2A), and the other one removing the predistillation column (Process 2B). In terms of energy costs, reductions of 17.9 and $67.3 \%$ were obtained in Processes $2 \mathrm{~A}$ and $2 \mathrm{~B}$, respectively, in comparison with Process 1 . In terms of capital expenditures (CAPEX), an increase of $22 \%$ is observed for Process 2A, while a decrease of $63 \%$ is achieved in Process $2 B$. Finally, even with an estimated ionic liquid cost of $100 \$ / \mathrm{kg}$, compared with an estimated $30 \$ / \mathrm{kg}$ for the NFM, the final ionic liquid cost will be around $15 \mathrm{MM} \$$, whereas the NFM initial investment is $2,7 \mathrm{MM} \$$ and $60 \mathrm{MM} \$$ /year related to make up flow.

In addition, the parametrization of the CPA EoS obtained previously ${ }^{30}$ was also implemented in Aspen Plus to compare the process simulation from two different thermodynamic package approaches. Both CPA and COSMO-SAC models similarly describe the extractive distillation process, confirming the COSMO-SAC model as a reliable a priori tool and setting the $\mathrm{CPA} \mathrm{EoS}$ as an alternative approach obtained from the regression of experimental VLE/VLLE data to describe these kinds of complex multicomponent systems.

\section{COMPUTATIONAL DETAILS}

2.1. COSMO-SAC Methodology and Parametrization of the CPA EoS in Aspen Plus. The ionic liquids used in the simulations were incorporated into Aspen Plus from the ILUAM database. Additional details can be found elsewhere. ${ }^{32}$ Both COSMO-SAC code 1 and CPA EoS were used to describe the VLE/VLLE data needed to simulate the extractive distillation processes. The COSMO-SAC model has been validated in previous studies as a reliable model to simulate the separation of aromatic hydrocarbons from different refinery streams. ${ }^{31,34-36}$ In addition, a massive validation was performed in this work, showing that the COSMO-SAC model qualitatively and quantitatively describes mixtures of hydrocarbons and ionic liquids.

The binary interaction parameters of the CPA EoS were obtained from the experimental VLE/VLLE data of binary systems \{aliphatic or aromatic + ionic liquid\} previously published. The molecular parameters for the ionic liquids were obtained from their liquid density and thermal capacity data found in the literature. ${ }^{28,37}$ The CPA EoS showed great 
robustness and accurate prediction of the VLE/VLLE of ternary systems \{aliphatic + aromatic + ionic liquid\}. ${ }^{28-30}$ Therefore, the parametrization of the CPA EoS has been implemented in Aspen Plus to check its suitability to simulate these kinds of systems.

The composition of the pyrolysis gasoline model used in this work is shown in Table 1 . This model has been adapted from the composition of a real pyrolysis gasoline stream ${ }^{2}$ and has been extensively used in other studies.

Table 1. Composition of the Pyrolysis Gasoline Model

$\begin{array}{ll}\text { hydrocarbon } & \text { composition/wt \% } \\ n \text {-hexane } & 11.3 \\ n \text {-heptane } & 11.3 \\ n \text {-octane } & 11.3 \\ \text { benzene } & 33.8 \\ \text { toluene } & 19.3 \\ p \text {-xylene } & 13.0\end{array}$

2.2. Conceptual Design of the Morphylane Process and the Ionic Liquid-Based Proposals. The conventional Morphylane process, here Process 1, is schematized in Figure 1. This process can be found in the literature for more in-depth information. ${ }^{33}$ The necessity of first removing the $\mathrm{C}_{8+}$ fraction in a conventional predistillation column (CDC) is remarkable. Then, the remaining aliphatics ( $n$-hexane and $n$-heptane) and aromatics (benzene and toluene) are separated in the extractive distillation column (EDC), where NFM is fed in the second stage (the condenser is the first one). Finally, NFM is recovered in a stripping column (SRC) at atmospheric pressure and recirculated to the top of the EDC, obtaining the aromatics by the top of the solvent recovery column.

Two ionic liquid-based processes have been proposed in this work. In Figure 2, Process $2 \mathrm{~A}$ is shown with the same configuration as in the conventional Morphylane process but using the ionic liquid as a mass agent. In this case, the recovery of the ionic liquid is carried out by a stripping column with nitrogen, as previous studies revealed its suitability. ${ }^{38,39}$ Then, the aromatic compounds, benzene and toluene, are separated from nitrogen in a flash drum (FD) at atmospheric pressure. In Figure 3, Process 2B is depicted. The BTX fraction is obtained from pyrolysis gasoline in the EDC without using a predistillation column. The recovery of the ionic liquid and the BTX separation from nitrogen are the same as in Process 2A.

For all the processes, FDs and heat exchangers were simulated by FLASH 2 and HEATER models, respectively. In addition, the PUMP block was used to describe the pressure increase needed to recycle the recovered solvent, and RADFRAC models were used to simulate the distillation and stripping columns.

2.3. Screening of Ionic Liquids in the EDC. The COSMO-SAC model was used to evaluate the efficiency of more than 100 ionic liquids as mass agents in the extractive distillation of binary mixtures $\{n$-octane + benzene $\}$. EDCs operating at $100 \mathrm{kPa}$ with 10 equilibrium stages were simulated with each of the ionic liquids. The ionic liquid was fed at the second stage, and the binary mixture $\{n$-octane + benzene $\}$ in the seventh stage at its bubble point to guarantee homogeneous conditions. A reflux ratio of 3 was established. The recovery of $n$ octane and benzene in the distillate and residue streams, respectively, was monitored as a function of the $S / F$ ratio $(1,3$, and 5 were tested). From these analyses, four ionic liquids, two with high extraction capacity ([4bmpy][TCM $]$ and $[\mathrm{bmim}]$ -

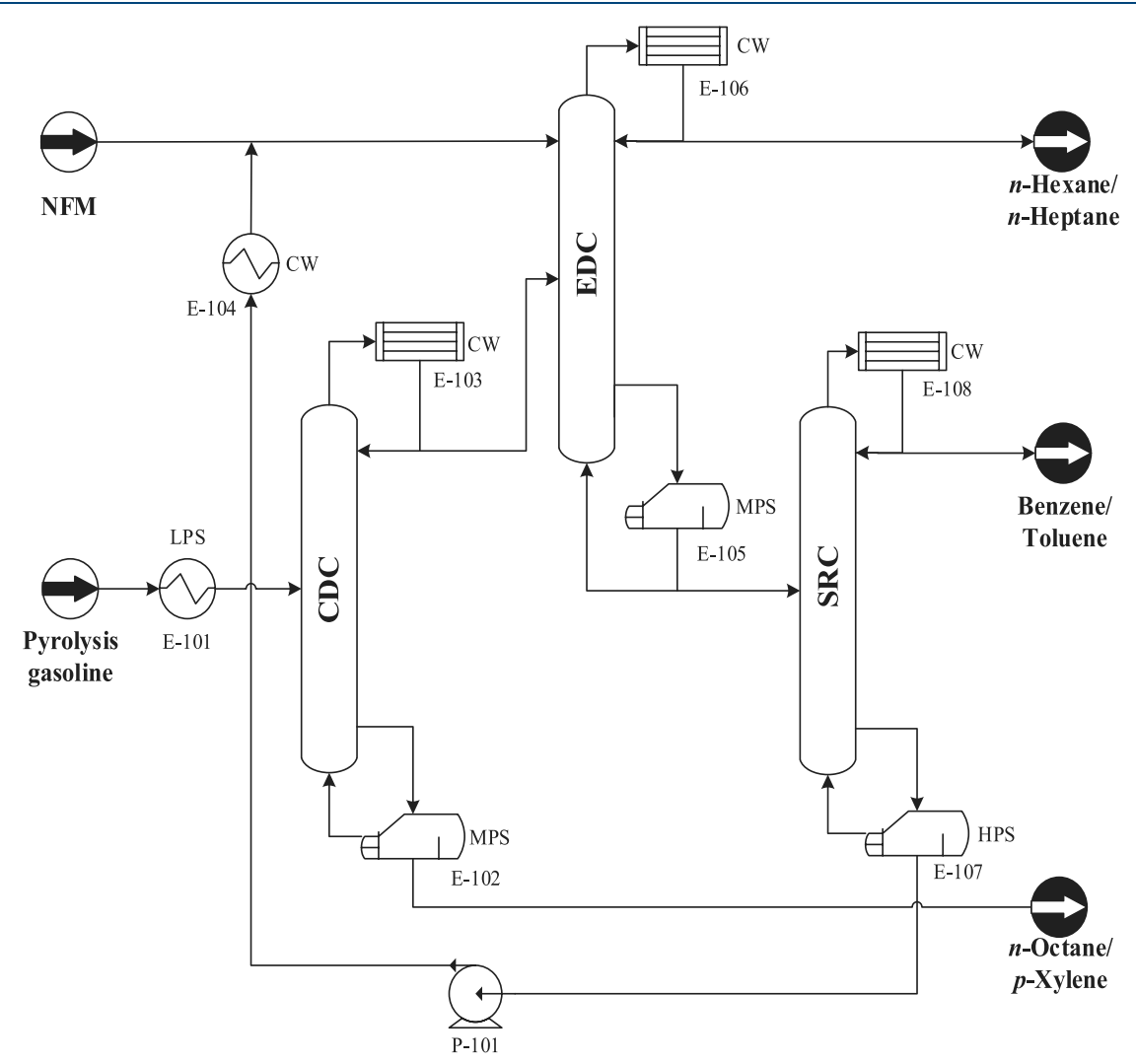

Figure 1. Morphylane process to separate the BTX from pyrolysis gasoline (Process 1). 


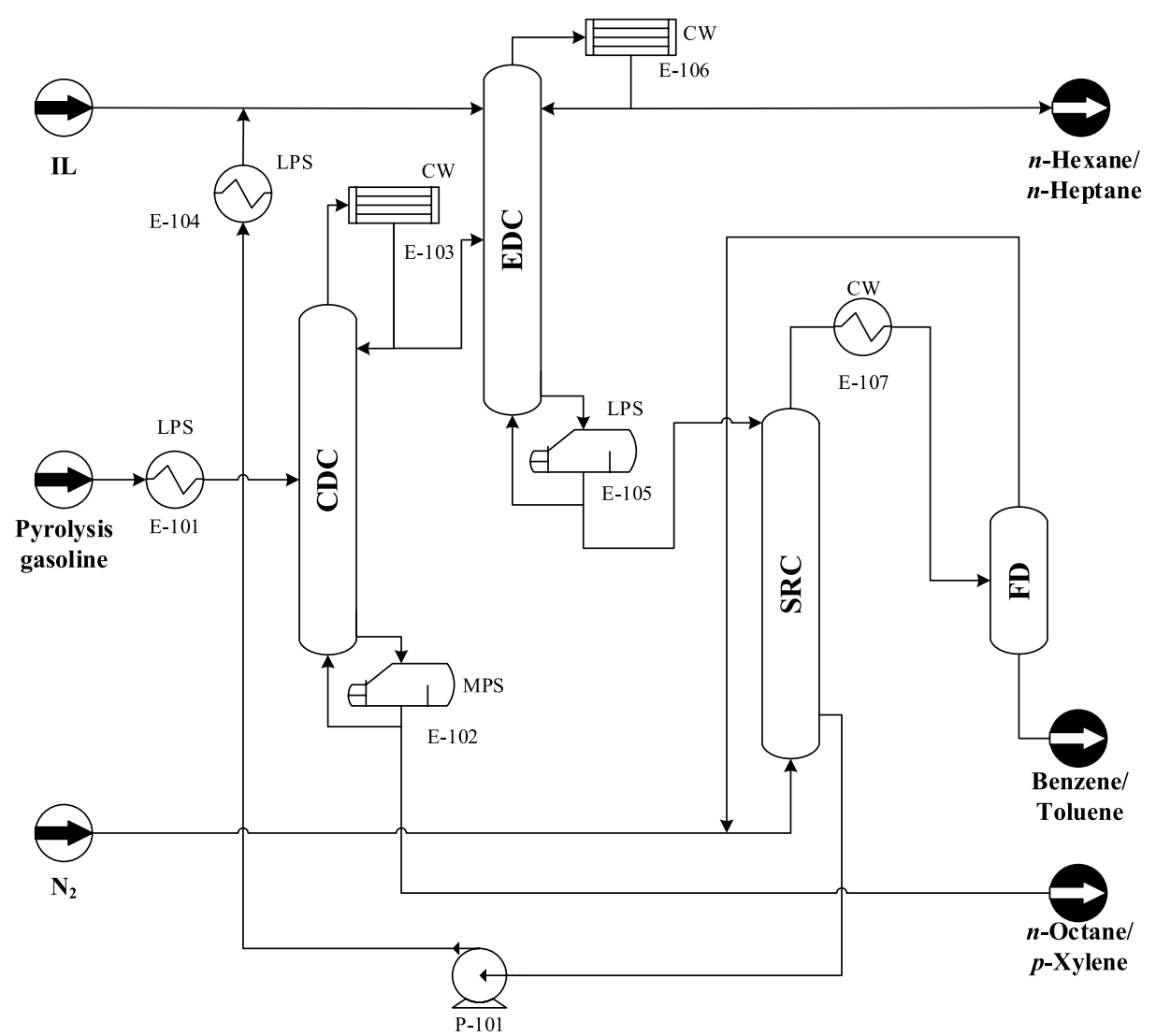

Figure 2. Ionic liquid-based proposal for the extractive distillation of BTX from pyrolysis gasoline with a predistillation column (Process 2A).

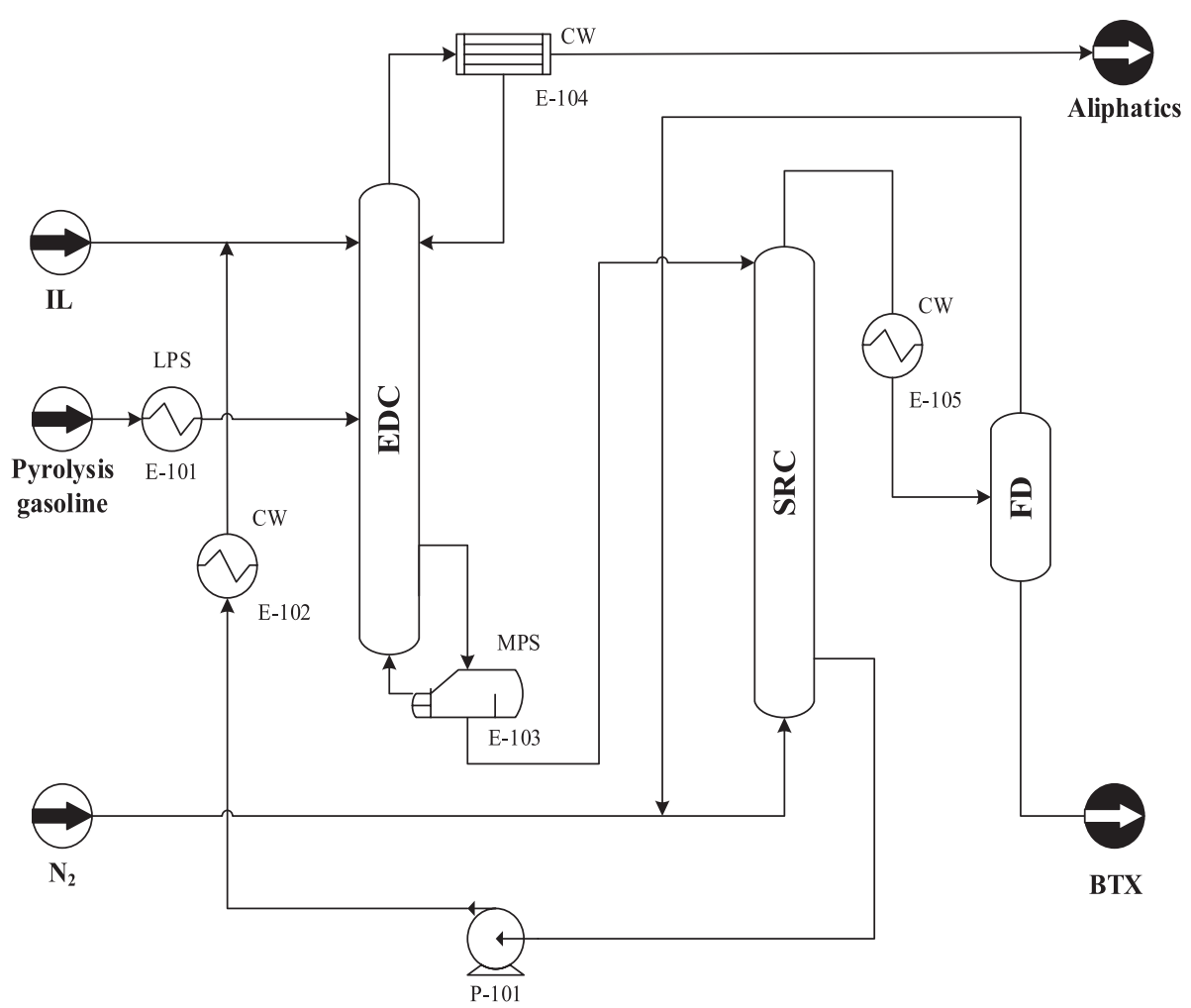

Figure 3. Ionic liquid-based proposal for the extractive distillation of BTX from pyrolysis gasoline without a predistillation column (Process $2 \mathrm{~B}$ ).

$[\mathrm{TCM}])$, one with intermediate extractive properties ([emim $]$ $[\mathrm{TCM}])$, and one with high selectivity ([emim] $[\mathrm{SCN}])$, were selected.
2.4. Sensitivity Analysis and Specification Design in the EDC. The COSMO-SAC model was used to conduct several sensitivity analyses in the EDC to determine the 

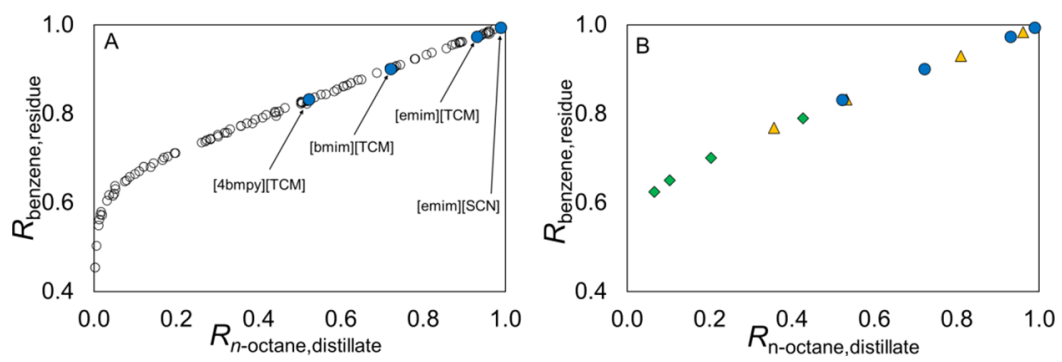

Figure 4. (A) Screening of ionic liquids in the EDC. Empty circles denote the ILUAM database with a S/F ratio of 5, whereas full circles denote the selected ionic liquids at the same S/F ratio. (B) Triangles and diamonds represent S/F ratios of 3 and 1, respectively, for the selected ionic liquids and full circles are the same points as in Figure 4A.

influence of the number of stages, feed stage, and reflux ratio on the recovery of $n$-octane and benzene with the four preselected ionic liquids. Three different $S / F$ ratios, namely 1,3 , and 5, were tested. In addition, the condenser and reboiler energy requirements were also compared for each ionic liquid under given conditions.

2.5. Equilibrium Design of the Ionic Liquid-Based Extractive Distillation Process. From the sensitivity analyses, $[\mathrm{emim}][\mathrm{SCN}]$ and $[\mathrm{emim}][\mathrm{TCM}]$ were selected as the best candidates. The COSMO-SAC model was used to simulate in equilibrium mode the EDC with these two ionic liquids to compare their performance in the extractive distillation of BTX from pyrolysis gasoline. A recovery of $n$-octane and benzene of $99.0 \mathrm{wt} \%$ was established in the EDC as a design condition. Also, from the results of the previous sensitivity analyses, the feed stage and reflux ratio were set to 6 and 2, respectively. The number of stages and the $S / F$ ratio were calculated as those that minimize the global energy consumption needed to achieve the separation goal in the EDC. The maximum temperature allowed in the process was set as the maximum operating temperature of each ionic liquid (452 and $360 \mathrm{~K}$ for [emim][TCM] and [emim] $[\mathrm{SCN}]$, respectively). In addition, the CPA EoS was used to simulate the EDC with [emim][TCM] as a solvent setting the same input conditions to compare the results obtained from two different thermodynamic models.

Subsequently, the COSMO-SAC model was established to simulate in equilibrium mode the solvent recovery column at atmospheric pressure using nitrogen as stripping gas. The mass flow of the nitrogen stream was established as the same of the aromatic hydrocarbon in the stream leaving the bottoms of the EDC. The purity of the recovered ionic liquid to be recirculated to the EDC was set to $99.9 \mathrm{wt} \%$. Finally, the separation of BTX and nitrogen was completed in a FD at $298.2 \mathrm{~K}$ and at atmospheric pressure.

2.6. Rate-Based Design of the Morphylane and the Ionic Liquid-Based Extractive Distillation Processes. The COSMO-SAC model was used to simulate all the processes in rate-based mode, which involves design based on kinetics and thermodynamics as well as column design based on flooding and pressure drop heuristics. The Chan-Fair-84 model was selected to do the calculations. ${ }^{40}$ In addition, the CPA EoS has been used to simulate the EDC in Process $2 \mathrm{~B}$ to compare the obtained results with COSMO-SAC's one. A sensitivity analysis was performed for both Process 1 and Process 2A to determine the optimal reflux ratio and number of stages in the predistillation column to remove $99.0 \mathrm{wt} \%$ of the $n$-octane and $p$-xylene from pyrolysis gasoline, calculating the energy requirements needed for each scenario. Then, recoveries of the key components of 99.9 wt \% were established as the design conditions for the EDC in the three processes. The evolution of the $S / F$ ratio with the number of stages needed to achieve the separation goal was determined, monitoring the global energy requirements for each case. The number of stages needed in the solvent recovery column to achieve the purity standard of the recovered solvent (99.9 wt \%) was calculated by a Design Spec (an Aspen Plus function with correlated process specifications with an independent variable), setting a ratio between mass flow rates of nitrogen and aromatic hydrocarbon in the feed stream of 1 . In the case of Process 1, the energy requirements in the solvent recovery column were also monitored. The FD for Process $2 \mathrm{~A}$ and $2 \mathrm{~B}$ was simulated at $298.2 \mathrm{~K}$ and at atmospheric pressure. These conditions were taken from the literature. ${ }^{38}$

During the simulations, an eye was kept on not to exceed the maximum pressure drop allowed and the limitations imposed by the column hydraulics and sizing heuristics. A maximum of $80 \%$ of the maximum downcomer choke flood, downcomer backup, and jet flood was established as limiting conditions for the internal design and diameter calculation. In addition, the maximum height/diameter ratio was set to a value of 30 .

Finally, a techno-economic comparison between the conventional process (Process 1) and the two ionic liquid-based processes (Processes 2A and $2 \mathrm{~B}$ ) was conducted with the results from the simulation with the COSMO-SAC model. The Aspen Economics tool was used to determine the capital and operating costs of all the processes from the utility consumption of each piece of equipment present in Figures 1-3 and using the utility prices available in the software database. Finally, a short solvent cost evaluation was accomplished.

\section{RESULTS AND DISCUSSION}

3.1. COSMO/Aspen Validation and Screening of Ionic Liquids. First, the validation of the COSMO/Aspen methodology has been collected in Figures S1 and S2 and Tables S1 and S2. COSMO-SAC code 1 was revealed as the best option to scan the ILUAM database for the separation of aromatics from aliphatics because the LLE and VLE are described with more accuracy than with COSMO-SAC code 2 and 3, standing the three equations as good qualitative descriptors of the experimental data.

Second, the screening results are shown in Figure 4. As seen in Figure 4A, the recovery of benzene and n-octane (mas$\left.\mathrm{s}_{\text {hydrocarbon,stream }} / \mathrm{mass}_{\text {hydrocarbon,feed }}\right)$ in residue and distillate streams, respectively, follows a direct relationship between them. In this context, observing the behavior of the four ionic liquids in Figure 4B, namely [emim] [SCN], [emim][TCM], $[\mathrm{bmim}][\mathrm{TCM}]$, and $[4 \mathrm{bmpy}][\mathrm{TCM}]$, it is concluded that any ionic liquid with an adequate $\mathrm{S} / \mathrm{F}$ ratio, independent of its extractive properties, will meet high recoveries of the key 
components. However, aromatic/aliphatic selectivity plays a dominant role in the separation. That is, the more selective through the aromatic compound is the ionic liquid (i.e., $[\mathrm{emim}][\mathrm{SCN}])$, the more recovery of both key components is achieved, being the opposite for the ionic liquids with higher extraction capacity (i.e., [4bmpy][TCM]). Finally, to narrow the ionic liquid matrix to a realistic list and delve into the operation parameters of the EDC, the four ionic liquids listed above are preselected. More than performance, this selection responds to their well-known low viscosities and adequate thermal stability, providing a useful guide in the field of aromatic/aliphatic separation with ionic liquids.

3.2. Performance of the Extractive Distillation Column: Sensitivity Analyses and Equilibrium Design. Following with the four preselected ionic liquids, the influence of the number of stages, feed stage, and reflux ratio on the recovery of the key components was studied to better understand the boundaries of the EDC. In this case, the distillate flow rate was set as the aliphatic flow rate in the feed stream. These data have been represented in Figures S3-S5 in the Supplementary Material not to overload the manuscript with preliminary analyses.

Figure S3 reports the recovery of benzene and $n$-octane as a function of the $S / F$ ratio and the number of stages. As evidence, the recovery of benzene is almost completely dependent on the nature of the ionic liquid and the $S / F$ ratio, the effect of the number of stages being slight, even at a low $\mathrm{S} / \mathrm{F}$ ratio because of the high benzene solubility in the ionic liquids. A more pronounced dependence on the nature of ionic liquids and the $\mathrm{S} / \mathrm{F}$ ratio is found in the recovery of $n$-octane because the effectiveness of the solvent must be enough to reverse the $n$ octane/benzene relative volatility (flipping phenomenon). Indeed, in those scenarios when the $n$-octane/benzene relative volatility is below the unity, an increase in the number of stages could even be detrimental for the recovery of $n$-octane, as can be seen when the $S / F$ ratio is below 5 for $[$ bmim $][\mathrm{TCM}]$ and [4bmpy][TCM].

Figure S4 shows the recovery of $n$-octane and benzene as a function of the $S / F$ ratio and the feed stage. As seen, there are an enriching number of stages to maximize the separation performance. The feed stage is located nearer the condenser when working with more efficient ionic liquids, [emim] [SCN] and [emim] [TCM], than for the others two ionic liquids. The stripping section is secondary in the design and only relevant for tuning high-purity scenarios. As for the number of stages, the effect of increasing the enriching section is more important for the recovery of $n$-octane than that for benzene. For [emim]$[\mathrm{SCN}]$ and $[\mathrm{emim}][\mathrm{TCM}]$ at a high S/F ratio, the recovery of $n$ octane and benzene increases up to 12 equilibrium stages and then decreases or remains almost constant. However, an increase in the enriching section favors the recovery of $n$-octane for all the scenarios with $[\mathrm{bmim}][\mathrm{TCM}]$ or $[4 \mathrm{bmpy}][\mathrm{TCM}]$.

Figure S5 depicts the recovery of $n$-octane and benzene as a function of the $S / F$ ratio and the reflux ratio. The reflux ratio hardly affects the performance of $[\mathrm{emim}][\mathrm{SCN}]$ and $[\mathrm{emim}]$ [TCM] for the highest $S / F$ ratio. At lower $S / F$ ratios, the recoveries first remain almost constant when the reflux ratio raises but then decrease. On the other hand, for [bmim] [TCM] and $[4 \mathrm{bmpy}][\mathrm{TCM}]$, the reflux ratio increase negatively impacts the recovery of both hydrocarbons in the whole interval studied, although the effect is more noticeable in the case of $n$-octane. In any case, the maximum performance is obtained for a reflux ratio of around 2 for $[\mathrm{emim}][\mathrm{SCN}]$ and $[\mathrm{emim}][\mathrm{TCM}]$, while the lowest value of reflux ratio studied is the optimum for [bmim] [TCM] and [4bmpy][TCM].

Results from Figures S3-S5 suggest $[\mathrm{emim}][\mathrm{SCN}]$ as the best solvent, except for the reflux ratio conclusions. Therefore, the aromatic selectivity of the ionic liquid is confirmed as the key property for the separation of the binary mixtures $\{n$-octane + benzene $\}$ independent of the operating conditions in the column. To extend this, in Figure 5, a new comparison is made

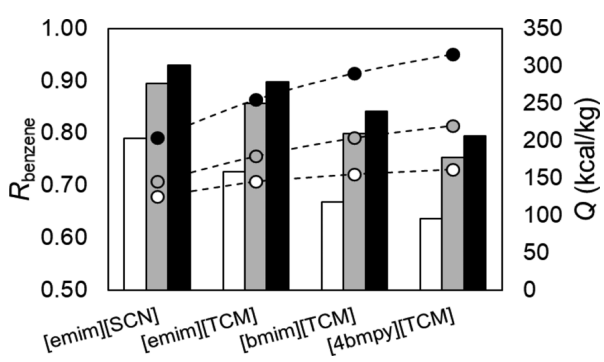

Figure 5. Energy consumption (dots) and recovery of benzene (bars) as a function of the $S / F$ ratio for seven equilibrium stages. $S / F=1-$ white-, 3-gray, and 5-black.

for the four ionic liquids selected, setting seven equilibrium stages, feed stage at the sixth stage, and a reflux ratio of 2 (optimal conditions for $[\mathrm{emim}][\mathrm{SCN}]$ ). Moreover, the energy consumption was monitored for each scenario. As expected, these results evidence that $[\mathrm{emim}][\mathrm{SCN}]$ provides the best performance with the lowest energy consumption followed by [emim $][$ TCM $]$.

Finally, a comparison between the $\mathrm{S} / \mathrm{F}$ ratio and overall energy consumption required to separate the BTX fraction from pyrolysis gasoline (recovery of $99.0 \mathrm{wt} \%$ of key components) with $[\mathrm{emim}][\mathrm{SCN}]$ and $[\mathrm{emim}][\mathrm{TCM}]$ is depicted in Figure 6. As observed, a minimum for both $\mathrm{S} / \mathrm{F}$ ratio and energy consumption is found within the range of number of stages studied. For [emim] [SCN], the optimal conditions were 11 equilibrium stages and a $\mathrm{S} / \mathrm{F}$ ratio of 4 , consuming less than 200 $\mathrm{kcal} / \mathrm{kg}$ of feed stream. For [emim][TCM], 13 equilibrium stages and a $\mathrm{S} / \mathrm{F}$ ratio of 6.7 were needed, consuming less than $400 \mathrm{kcal} / \mathrm{kg}$ of feed stream. Therefore, [emim] [SCN] offers the best results confirming selectivity as optimization criteria for the design of the EDC.

However, from a process point of view, the thermal stability of the ionic liquids is essential. The maximum operating temperature for $[\mathrm{emim}][\mathrm{SCN}]$ is $360 \mathrm{~K}^{41}$ This temperature is even exceeded in the bottoms of the EDC $(374 \mathrm{~K})$, and higher temperatures are expected to be achieved in the recovery step if vacuum conditions are avoided. Because vacuum cost clearly impacts process feasibility, it is not evaluated in this work. Other selective ionic liquids present similar limitations. Therefore, [emim] $[\mathrm{TCM}]$, whose maximum operating temperature is 452 $\mathrm{K},{ }^{42}$ overcomes this limitation and stands as the best solvent studied here.

The whole process of extractive distillation of BTX from pyrolysis gasoline with [emim] $[\mathrm{TCM}]$, including the stripping with nitrogen to recover the ionic liquid, has been simulated in equilibrium mode. Results are listed in Table 2, collecting the main operating conditions. The separation of BTX from nitrogen is completely achieved in a FD. As seen, the premise of recovering $99.0 \mathrm{wt} \%$ of BTX is reached in the EDC avoiding liquid-phase splitting. The purity of the ionic liquid achieved in the stripping column with three equilibrium stages is enough to 

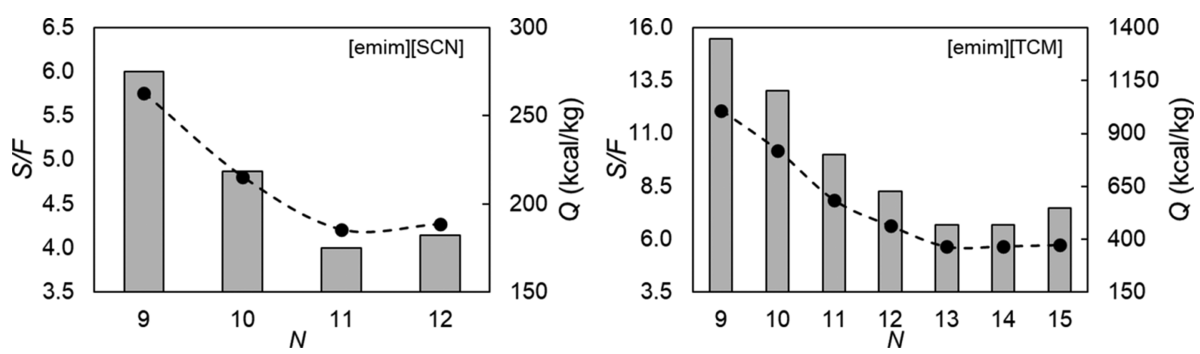

Figure 6. S/F ratio (bars) and energy consumption (dots) as a function of the number of stages $(N)$ in the design of the EDC to recover $99 \%$ of the key components with $[\mathrm{emim}][\mathrm{SCN}]$ and $[\mathrm{emim}][\mathrm{TCM}]$. The feed stage is the 6th, and the reflux ratio is set to 2 in both cases.

Table 2. Operating Conditions in Equilibrium Mode for the Extractive Distillation of BTX from Pyrolysis Gasoline with $[$ emim $][$ TCM $]$ as a Solvent

\begin{tabular}{|c|c|c|}
\hline EDC & COSMO-SAC & CPA \\
\hline temperature $/ \mathrm{K}$ & $360-397$ & $361-409$ \\
\hline pressure $/ \mathrm{kPa}$ & 101.3 & 101.3 \\
\hline $\mathrm{S} / \mathrm{F}$ ratio & 6.7 & 6.7 \\
\hline equilibrium steps & 13 & 13 \\
\hline feed stage & 6 & 6 \\
\hline reflux ratio & 2 & 2 \\
\hline $\mathrm{B} / \mathrm{T} / \mathrm{X}$ yield $\%$ & $99.00 / 99.96 / 100.00$ & $99.96 / 99.99 / 100.0$ \\
\hline BTX purity/wt $\%$ & 99.80 & 99.98 \\
\hline alkane purity/wt $\%$ & 99.00 & 99.95 \\
\hline$Q_{\mathrm{reb}} /{\mathrm{kcal} \cdot \mathrm{kg}^{-1}}$ & 294 & 311 \\
\hline$Q_{\text {cond }} / \mathrm{kcal} \mathrm{kg}^{-1}$ & 69.5 & 71.0 \\
\hline \multicolumn{2}{|c|}{ solvent recovery column (SRC) } & COSMO-SAC \\
\hline \multicolumn{2}{|c|}{ temperature $/ \mathrm{K}$} & $388-381$ \\
\hline \multicolumn{2}{|l|}{ pressure $/ \mathrm{kPa}$} & 101.3 \\
\hline \multicolumn{2}{|l|}{ equilibrium steps } & 3 \\
\hline \multicolumn{2}{|c|}{ nitrogen/BTX mass flowrate ratio } & 1 \\
\hline \multicolumn{2}{|l|}{$\mathrm{B} / \mathrm{T} / \mathrm{X}$ yield/\% } & 99.7/99.0/97.6 \\
\hline \multicolumn{2}{|l|}{ BTX purity/wt $\%$} & 99.9 \\
\hline \multicolumn{2}{|c|}{ ionic liquid recovered purity/wt $\%$} & \\
\hline
\end{tabular}

recirculate it to the process without disturbing the performance of the EDC.

Finally, the results of the simulation with the CPA EoS are also collected in Table 2 to be compared with those obtained with the COSMO-SAC model. The same input conditions as in the simulation with the COSMO-SAC model were set, determining the separation yield, purities, and energy requirements. As seen, the simulation of the EDC with the CPA EoS results in higher separation efficiencies, overcoming the standards established in the simulation with the COSMO-SAC model. This point agrees with previously published results, where the COSMO-SAC underestimation of the aromatic solubility in the ionic liquids was noted. $^{22,43}$ That is, the separation efficiency is slightly underestimated with the COSMO-SAC model, resulting in an overestimation of the number of stages and $S / F$ ratio needed to achieve the separation standards. Indeed, the temperature profile is quite similar, leading to similar energy consumptions. In this way, the ability of the CPA EoS to simulate the extractive distillation of BTX from pyrolysis gasoline in equilibrium mode is checked. However, the rest of the process was unable to be simulated by the CPA EoS because of the lack of validated binary interaction parameters regarding nitrogen, hydrocarbons, and [emim][TCM], setting the COSMO/Aspen methodology as an ideal tool to evaluate the whole process.

3.3. Rate-Based Extractive Distillation Techno-Economic Comparison between the Morphylane Process and the Ionic Liquid-Based Proposals with COSMO-SAC. Once the feasibility of [emim][TCM] as a mass agent for the extractive distillation of BTX from pyrolysis gasoline has been checked in equilibrium mode, the whole extractive distillation process has been rigorously designed in rate-based mode, covering thermodynamic basis, mass transfer issues, and sizing heuristic. A more realistic approach is needed to obtain more reliable and useful results not only from an academic point of view but also from an industrial one. Process 1 was optimized to establish a reference and compared with Processes $2 \mathrm{~A}$ and $2 \mathrm{~B}$. Because of the absence of concrete commercial references, the simulation of Process 1 has been based on qualitative information about the scheme of the Morphylane process available in the literature. $2,33,44-47$

3.3.1. Rate-Based Simulation of the Morphylane Process with COSMO-SAC. First, Figure 7A shows the evolution of the number of stages and global energy requirements of the predistillation column as a function of the reflux ratio, setting the feed stage at the 65th. The aim is to reduce the content of $n$ octane and $p$-xylene in the pyrolysis gasoline below 1 wt \%. As
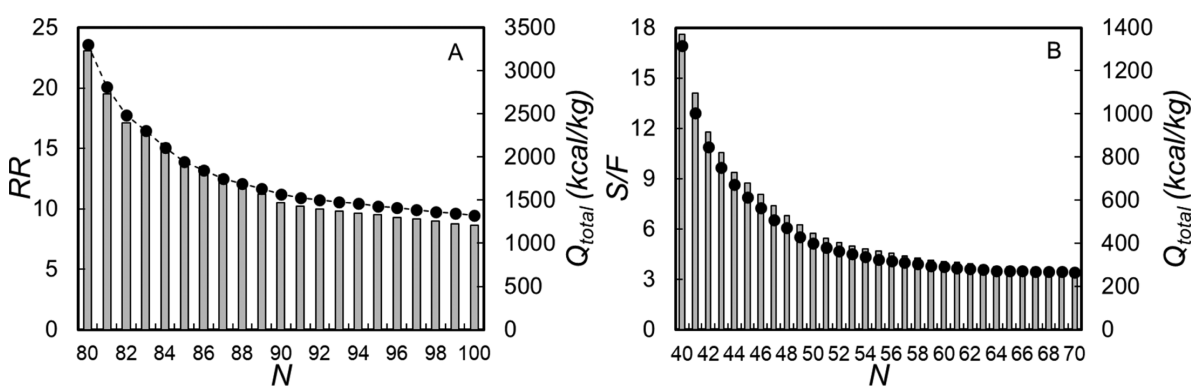

Figure 7. Sensitivity analysis of the main operating variables of Process 1 . (A) Evolution of the reflux ratio (RR) with the number of stages $(N)$ in the predistillation column. (B) Evolution of the S/F with the number of stages in the EDC. Dots represent global energy consumption of the process for each scenario. 
Table 3. Operating Conditions for the Morphylane Process (Process 1) Simulated in Rate-Based Mode with the COSMO-SAC Model

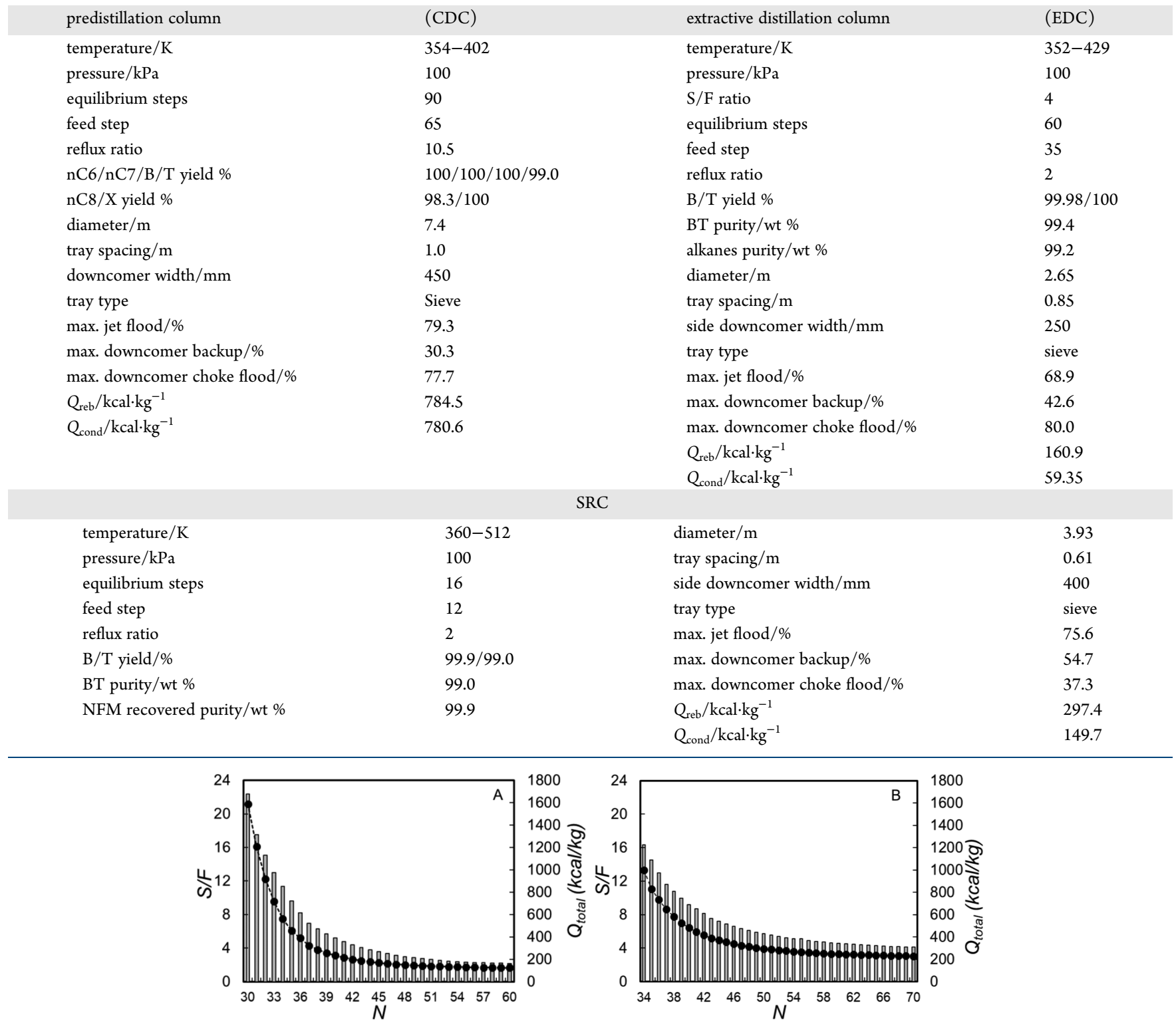

Figure 8. S/F ratio (bars) and energy consumption (dots) as a function of the number of stages $(N)$ in the EDC to recover $99.9 \%$ of benzene with [emim] [TCM] for Processes 2A (A) and 2B (B). The feed stage is set to the 25th and RR to 2 .

can be observed, energy consumption is reduced with the increase in the number of stages. From 90 equilibrium stages and a reflux ratio of 10.5 , the decrease in energy requirements is less relevant, establishing these values as the operating conditions in the predistillation column.

Next, the S/F ratio needed to recover 99.9 wt \% of benzene and toluene by bottoms of the EDC for different number of stages is represented in Figure $7 \mathrm{~B}$. The global energy requirements for each scenario have also been depicted. The reflux ratio and feed stage were kept at 2 and 35, respectively, according to the results obtained in section 3.2. As seen, an increase in the number of stages leads to a decrease of solvent and energy requirements in the EDC up to 60 equilibrium stages. For a higher number of stages, the decrease of solvent and energy consumption is not so significant. Thus, a $S / F$ ratio of 4 and 60 equilibrium stages have been established, consuming globally $220 \mathrm{kcal} / \mathrm{kg}$ of gasoline-treated.
Finally, the number of stages needed in the solvent recovery column to obtain NFM with a minimum purity of $99.9 \mathrm{wt} \%$ was calculated, feeding the stream at the sixth stage and also keeping the reflux ratio at 2 . The energy consumption was also determined in the reboiler and condenser. As a result, 10 equilibrium stages and $447 \mathrm{kcal} / \mathrm{kg}$ of pyrolysis gasoline fed were required to achieve the purity standard for the recovered NFM. Therefore, the reboiler of the predistillation column represents more than $63 \%$ of the total reboiler consumption, while the condenser of the predistillation column accounts for $80 \%$ of the total condenser consumption in Process 1 . The two additional heat exchangers depicted in Figure 1 (E-101 and E-104) consume 30 and $251 \mathrm{kcal} / \mathrm{kg}$ of fed gasoline, respectively. That is, the energy requirements of the predistillation column are $62.3 \%$ of the total energy requirements of Process 1 . However, the high temperature of the stream leaving the solvent recovery column by bottoms could be used to reduce the energy 
Table 4. Operating Conditions for the Ionic Liquid-Based Extractive Distillation Process (Process 2A) Simulated in Rate-Based Mode with the COSMO-SAC Model

\begin{tabular}{|c|c|c|c|}
\hline \multicolumn{4}{|c|}{ EDC } \\
\hline temperature $/ \mathrm{K}$ & $352-376$ & section 1 stages & $2-25$ \\
\hline pressure $/ \mathrm{kPa}$ & 101.3 & diameter $/ \mathrm{m}$ & 2.25 \\
\hline $\mathrm{S} / \mathrm{F}$ ratio & 3 & tray spacing $/ \mathrm{m}$ & 0.8 \\
\hline equilibrium steps & 48 & downcomer width $/ \mathrm{mm}$ & 275 \\
\hline feed stage & 25 & tray type & sieve \\
\hline reflux ratio & 2 & max. jet flood/\% & 79.0 \\
\hline $\mathrm{B} / \mathrm{T}$ yield $\%$ & $99.99 / 100.0$ & max. downcomer backup/\% & 34.8 \\
\hline BT purity/wt $\%$ & 99.8 & max. downcomer choke flood/\% & 68.0 \\
\hline alkanes purity/wt $\%$ & 99.4 & section 2 stages & $26-48$ \\
\hline$Q_{\mathrm{reb}} / \mathrm{kcal} \cdot \mathrm{kg}^{-1}$ & 98.8 & diameter $/ \mathrm{m}$ & 3.56 \\
\hline$Q_{\text {cond }} / \mathrm{kcal} \cdot \mathrm{kg}^{-1}$ & 51.3 & tray spacing $/ \mathrm{m}$ & 1.0 \\
\hline & & downcomer width $/ \mathrm{mm}$ & 450 \\
\hline & & tray type & Sieve \\
\hline & & $\max$. jet flood $/ \%$ & 68.9 \\
\hline & & max. downcomer backup/\% & 74.0 \\
\hline & & max. downcomer choke flood/\% & 75.8 \\
\hline \multicolumn{4}{|c|}{ SRC } \\
\hline temperature/K & $366-349$ & diameter/m & 3.19 \\
\hline pressure $/ \mathrm{kPa}$ & 101.3 & tray spacing/m & 0.6 \\
\hline equilibrium steps & 12 & side downcomer width/mm & 325 \\
\hline nitrogen/BTX mass flowrate ratio & 1 & tray type & sieve \\
\hline $\mathrm{B} / \mathrm{T}$ yield $/ \%$ & $99.9 / 98.8$ & max. jet flood/\% & 79.8 \\
\hline BT purity/wt $\%$ & 99.8 & max. downcomer backup/\% & 73.9 \\
\hline ionic liquid recovered purity/wt $\%$ & 99.9 & max. downcomer choke flood/\% & 74.7 \\
\hline
\end{tabular}

Table 5. Operating Conditions for the Ionic Liquid-Based Extractive Distillation Process (Process 2B) Simulated in Rate-Based Mode with the COSMO-SAC Model

\begin{tabular}{|c|c|c|c|}
\hline \multicolumn{4}{|c|}{ EDC } \\
\hline temperature $/ \mathrm{K}$ & $361-388$ & section 1 stages & $2-25$ \\
\hline pressure $/ \mathrm{kPa}$ & 101.3 & diameter $/ \mathrm{m}$ & 3.65 \\
\hline $\mathrm{S} / \mathrm{F}$ ratio & 5 & tray spacing $/ \mathrm{m}$ & 1.0 \\
\hline equilibrium steps & 56 & downcomer width $/ \mathrm{mm}$ & 490 \\
\hline feed stage & 25 & tray type & Sieve \\
\hline reflux ratio & 2 & $\max$.jet flood $/ \%$ & 76.9 \\
\hline $\mathrm{B} / \mathrm{T} / \mathrm{X}$ yield $\%$ & $99.99 / 100.0 / 100.0$ & max. downcomer backup/\% & 74.7 \\
\hline BTX purity/wt \% & 99.8 & max. downcomer choke flood/\% & 78.6 \\
\hline Alkanes purity/wt $\%$ & 99.9 & section 2 stages & $26-56$ \\
\hline$Q_{\mathrm{reb}} / \mathrm{kcal} \cdot \mathrm{kg}^{-1}$ & 191.9 & diameter $/ \mathrm{m}$ & 4.46 \\
\hline$Q_{\text {cond }} / \mathrm{kcal} \cdot \mathrm{kg}^{-1}$ & 72.8 & tray spacing $/ \mathrm{m}$ & 1.0 \\
\hline & & downcomer width/mm & 550 \\
\hline & & tray type & sieve \\
\hline & & $\max$. jet flood/\% & 75.3 \\
\hline & & max. downcomer backup/\% & 66.9 \\
\hline & & max. downcomer choke flood/\% & 76.1 \\
\hline \multicolumn{4}{|c|}{ SRC } \\
\hline temperature/K & $381-368$ & diameter $/ \mathrm{m}$ & 3.49 \\
\hline pressure $/ \mathrm{kPa}$ & 101.3 & tray spacing/m & 0.85 \\
\hline equilibrium steps & 10 & side downcomer width $/ \mathrm{mm}$ & 400 \\
\hline nitrogen/BTX mass flowrate ratio & 1 & tray type & sieve \\
\hline $\mathrm{B} / \mathrm{T} / \mathrm{X}$ yield/\% & $99.9 / 99.5 / 98.0$ & $\max$. jet flood $/ \%$ & 77.2 \\
\hline BTX purity/wt \% & 99.8 & max. downcomer backup/\% & 41.6 \\
\hline ionic liquid recovered purity/wt $\%$ & 99.9 & max. downcomer choke flood/\% & 65.7 \\
\hline
\end{tabular}

consumption in the reboiler of the conventional distillation column. Nevertheless, this has not be considered the scope of this work.

Once the main operating variables were set, the internals were selected to obtain the column diameters, dealing with hydraulics and sizing limitations. The diameter of the predistillation column is considerably larger than those of the other two columns, needing also more space between stages. All the plates were the sieve type as these are the cheapest, simplest, and can be utilized for a great operating interval. ${ }^{48}$ The operating 
conditions and design variables of the main pieces of equipment of Process 1 are collected in Table 3.

3.3.2. Rate-Based Simulation of the Ionic Liquid-Based Proposals with COSMO-SAC. Here, Processes $2 \mathrm{~A}$ and $2 \mathrm{~B}$ were simulated to compare the solvent and energy consumption with those in Process 1 and set the best process configuration and operating conditions for the extractive distillation of BTX from pyrolysis gasoline. For Process $2 \mathrm{~A}$, the predistillation column was considered the same as in Process 1 . In Figure 8A,B, the evolution of the S/F ratio needed to recover $99.9 \mathrm{wt} \%$ of BTX for different number of stages in the EDC column was represented for both Processes $2 \mathrm{~A}$ and 2B, respectively. According to the conclusions obtained in section 3.2, the RR was set to 2 and the feed stage to the 25th, increasing the stripping section up to the purity grade is achieved. Also, the energy consumption for each operating condition was determined. As expected, the $\mathrm{S} / \mathrm{F}$ ratio decreases with the increase of the number of stages up to a certain point from which it remains almost constant. From these results, a S/F ratio of 3 and 48 equilibrium stages and a $\mathrm{S} / \mathrm{F}$ ratio of 5 and 56 equilibrium stages were selected for Processes $2 \mathrm{~A}$ and $2 \mathrm{~B}$, respectively. Although a higher $\mathrm{S} / \mathrm{F}$ ratio is required in Process $2 \mathrm{~B}$, the separation of the key components is properly achieved with a realistic solvent consumption and without the necessity of the predistillation column. In addition, a purity of $99.8 \mathrm{wt} \%$ is obtained in Processes 2A and 2B, being 99.4 wt \% in Process 1.

Regarding the energy consumption in the EDC, Process $2 \mathrm{~A}$ requires $98.8 \mathrm{kcal} / \mathrm{kg}$ in the reboiler and $51.3 \mathrm{kcal} / \mathrm{kg}$ in the condenser, while Process 2B 191.9 and $72.8 \mathrm{kcal} / \mathrm{kg}$ in the reboiler and condenser, respectively. These energy consumptions are similar to those found in the literature for similar processes. $^{23,49}$ Concerning the solvent recovery column, no energy consumption is required. The number of stages needed to recover [emim] [TCM] with a purity of $99.9 \mathrm{wt} \%$ was 12 for Process 2A and 10 for Process 2B. As for the recovery of BTX from nitrogen, it is completely achieved in a FD at atmospheric pressure and $298.2 \mathrm{~K}$. In summary, the energy consumption for heating is reduced 27 and $83 \%$ for Processes $2 \mathrm{~A}$ and $2 \mathrm{~B}$, respectively, compared to Process 1 , while the energy consumption for cooling is reduced 28 and $70 \%$, respectively. The removal of the predistillation column is crucial because it represents the most significant percentage of the energy consumption of the process. Thus, despite its higher solvent and energy consumption in the EDC, Process $2 \mathrm{~B}$ represents the best process configuration among the three considered in this work.

The internals of the column were selected to obtain suitable column diameters, in compliance with hydraulics, and sizing heuristics, and without exceeding the maximum pressure drop allowed. ${ }^{50}$ A summary of the main operating conditions of both processes is collected in Tables 4 and 5. As can be seen, the EDC was divided into two sections for both processes because of the significant variation of the liquid and vapor flows through the column. These issues were not found in the stripping column. A greater EDC and a SRC are needed in Process 2B because of the higher amount of ionic liquid and gasoline fed. Also, higher tray spacing and wider downcomers were needed in Process $2 \mathrm{~B}$ to avoid jet and choke flood. However, differences would not lead to a remarkable increase in the process costs, even more when the predistillation is removed.

3.3.3. Operating and Capital Costs of the Morphylane Process and the lonic Liquid-Based Proposals. In Figure 9, the CAPEX and unitary operating costs reported by the Aspen Plus

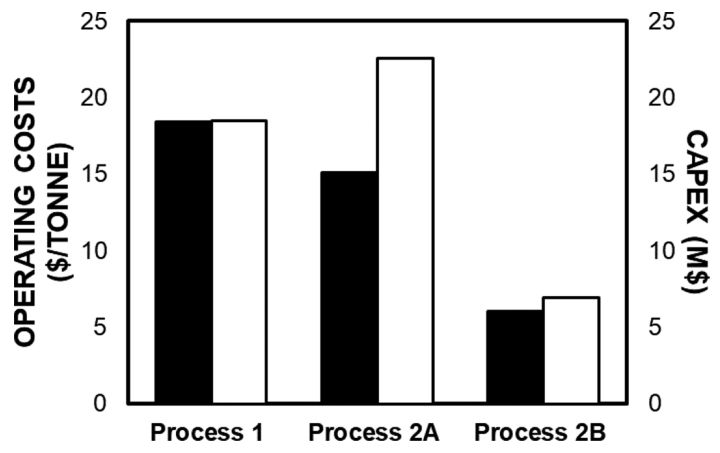

Figure 9. Operating costs per ton of pyrolysis gasoline-treated (black) and capital expenditures (white) for Processes 1, 2A, and 2B.

Economics tool for the three processes evaluated in this work have been depicted. On the one hand, in terms of operating costs, the great advantage of [emim] [TCM] over NFM is clear, even for Process 2A. The unitary operating costs for Process 1 turned out $18.4 \$ /$ ton of fed gasoline, and they are reduced 17.9 and $67.3 \%$ for Processes $2 \mathrm{~A}$ and $2 \mathrm{~B}$, respectively. On the other hand, Process $2 \mathrm{~A}$ requires more capital investment than Process 1 (a $21.7 \%$ higher) because of its larger EDC and the need for more pieces of equipment. However, Process $2 \mathrm{~B}$ is confirmed as the optimum process also in terms of CAPEX, achieving a reduction of $62.7 \%$ in comparison with Process 1 . It must be remarked that the ionic liquid price is relatively higher than that of conventional solvents. Lei et al. took a price of $91.03 \$ / \mathrm{kg}$ for the $[\mathrm{mmpy}]\left[\mathrm{BF}_{4}\right]$, three times higher than the price established for the sulfolane or NFM. ${ }^{23}$ According to this, Process 1 had a solvent investment of $2.7 \mathrm{MM} \$$, related to a process residence time of $0.5 \mathrm{~h}$ and $30 \$ / \mathrm{kg}$ price; Process $2 \mathrm{~B}$ demands $15 \mathrm{MM} \$$ of investment in the ionic liquid in the same scenario but with a price of $100 \$ / \mathrm{kg}$. However, the nonvolatile character of the ionic liquid imposes the advantage of negligible losses of solvent, imposing no make-up requirements; NFM losses in the process are around $250 \mathrm{~kg} / \mathrm{h}$, which demands $60 \mathrm{MM} \$$ /year operating costs associated with the solvent. Although these are rough estimations, the ionic liquid role in solvent costs seems to be highly favorable.

On the other hand, improvements are not only found from the economic view, but also the performance achieved with [emim][TCM] is higher than that with NFM because it is possible to separate BTX from pyrolysis gasoline in only one column. In addition, the assumable hydraulic problems due to the high viscosity of the ionic liquids were not found with the internal configuration set in Processes $2 \mathrm{~A}$ and 2B. It is true that Process $2 \mathrm{~B}$ demands a new plant configuration and construction from scratch, but in the long run, it is a quite better option in terms of energy consumption and performance. From the light of these results, the ionic liquid-based extractive distillation technology stands as a promising technology to obtain aromatics compounds from refinery streams.

3.4. Exploring the CPA EoS as a Regressive Alternative to Simulate Ionic Liquid-Based Processes. The EDC of Process $2 \mathrm{~B}$ has also been simulated in rate-based mode, implementing the parametrization of the CPA EoS obtained previously from experimental VLE/VLLE data. ${ }^{28-30}$ The aim is to check the suitability of the CPA EoS to describe the separation at hand. The details of the parametrization of the CPA EoS have been previously described elsewhere, ${ }^{51,52}$ so only the results obtained in the simulation of the EDC are discussed here. The same input conditions as those for Process 2B 
Table 6. Operating Conditions for the Extractive Distillation Column of Process 2B Simulated in Rate-Based Mode with the CPA EoS

\begin{tabular}{|c|c|c|c|}
\hline \multicolumn{4}{|c|}{ EDC } \\
\hline temperature $/ \mathrm{K}$ & $361-399$ & section 1 stages & $2-25$ \\
\hline pressure $/ \mathrm{kPa}$ & 101.3 & diameter $/ \mathrm{m}$ & 2.11 \\
\hline $\mathrm{S} / \mathrm{F}$ ratio & 5 & tray spacing/m & 1.00 \\
\hline equilibrium steps & 30 & downcomer width $/ \mathrm{mm}$ & 200 \\
\hline feed stage & 25 & tray type & sieve \\
\hline reflux ratio & 2 & $\max$. jet flood $/ \%$ & 79.7 \\
\hline $\mathrm{B} / \mathrm{T}$ yield $\%$ & $99.9 / 100 / 100$ & max. downcomer backup/\% & 38.5 \\
\hline BT purity/wt \% & 99.99 & max. downcomer choke flood/\% & 74.6 \\
\hline alkane purity/wt $\%$ & 99.90 & section 2 stages & $25-29$ \\
\hline$Q_{\mathrm{reb}} / \mathrm{kcal} \cdot \mathrm{kg}^{-1}$ & 215.6 & diameter $/ \mathrm{m}$ & 3.19 \\
\hline$Q_{\text {cond }} / \mathrm{kcal} \cdot \mathrm{kg}^{-1}$ & 66.6 & tray spacing $/ \mathrm{m}$ & 1.0 \\
\hline & & downcomer width $/ \mathrm{mm}$ & 238 \\
\hline & & tray type & sieve \\
\hline & & max. jet flood $/ \%$ & 73.7 \\
\hline & & max. downcomer backup/\% & 38.7 \\
\hline & & max. downcomer choke flood $/ \%$ & 76.0 \\
\hline
\end{tabular}

simulated with the COSMO-SAC model have been introduced to Aspen Plus. The results obtained with the CPA EoS are collected in Table 6.

As can be inferred, the simulation of the EDC with the CPA EoS results in a fewer number of stages than that with the COSMO-SAC model for the same separation goal. These results agree with those obtained above for the simulation in equilibrium mode and those reported previously in the literature. $^{22,43}$ That is, because the COSMO-SAC model underestimates the extraction capacity of ionic liquids, the number of stages needed to achieve the same separation performance for the same input data is overestimated. However, temperature profile and energy consumptions are quite similar with both models ( $10 \%$ deviations), confirming the suitability of the COSMO-SAC model to describe the extractive distillation of BTX from pyrolysis gasoline accurately. On the other hand, the CPA EoS is useful to describe the EDC even with a rate-based approach, opening an interesting way to further develop this EoS as thermodynamic basis for simulation purposes. In this way, this work is the culmination of a series of papers where experimental VLE/VLLE data have been satisfactorily modeled and predicted with the CPA EoS to obtain and implement in Aspen Plus a model able to describe a complex multicomponent separation accurately. Furthermore, all this background can be used to implement in Aspen Plus other parametrizations of the CPA EoS to simulate other separations of interest, such as cyclohexane/ cyclohexene/benzene or alkylcycloalkane/aromatic separations. $^{53}$

\section{CONCLUSIONS}

This work systematically explores extractive distillation with ionic liquids as a replacement of the Morphylane process, covering solvent screening, parametric study at process scale, rigorous rate-based design, and techno-economic comparison of both technologies. This work uses a COSMO/Aspen methodology, which is massively validated against experimental data, whereas a CPA EoS regressive model previously gathered is also tested for comparison purposes at the process scale.

The validation of the COSMO/Aspen methodology provides an a priori tool to scan a high number of ionic liquids as entrainers, following a gasoline preheating strategy to overcome heterogeneous extractive distillation issues. The aromatic/ aliphatic selectivity and solvent consumption, in that order, are the key parameters of the EDC, whereas the number of stages, RR, and feed stage impose less pronounced changes in separation factors. Dealing with the whole process scheme, issues related to thermal stability pointed [emim] [TCM] as the selected solvent, in line with previous literature.

At the process scale, $[\mathrm{emim}][\mathrm{TCM}]$ can draw both conventional and new process schemes because of the ability to change the volatility order of the key components ( $n$-octane/ benzene) in favor of the alkane. Rigorous design, considering mass transfer, allowed inferring that the role of the ionic liquid to improve operating costs is double. Although to a less extent, the costs are reduced only using this nonvolatile solvent. However, the key contribution of the ionic liquid is drafting a new scheme that incorporates the $\mathrm{C}_{8}$ fraction (n-octane and xylene in this work) in the aromatic/aliphatic separation, which intensified the process at the same time that drastically reduced operating cost around $67 \%$ in comparison with the Morphylane process. Regarding solvent costs, investment is higher for the ionic liquidbased technology, but operating costs related to NFM make-up draw positive conclusions in favor of ionic liquids. In addition, the CAPEX was sharply reduced $(62.7 \%$ regarding the Morphylane process) with this new process configuration.

Finally, two modeling strategies are evaluated in this work, revealing the goodness of the COSMO/Aspen methodology and enabling the use of the CPA EoS as a useful model for studying hydrocarbon separations at the process scale.

\section{ASSOCIATED CONTENT}

\section{SI Supporting Information}

The Supporting Information is available free of charge at https://pubs.acs.org/doi/10.1021/acs.iecr.1c04363.

Validation of COSMO predictions of liquid-liquid and vapor-liquid equilibrium data, recoveries of benzene and $n$-octane as a function of $S / F$ ratio, number of equilibrium stages, feed stage, and reflux ratio, and references collected for the validation of the COSMO/Aspen methodology (PDF) 


\section{AUTHOR INFORMATION}

\section{Corresponding Author}

Pablo Navarro - Departamento de Ingeniería Química, Universidad Autónoma de Madrid, 28049 Madrid, Spain; ๑ orcid.org/0000-0002-0017-3898;

Email: pablo.navarro@uam.es

\section{Authors}

Miguel Ayuso - Departamento de Ingeniería Química y de Materiales, Universidad Complutense de Madrid, 28040

Madrid, Spain; @ orcid.org/0000-0003-1521-6894

Cristian Moya - Departamento de Ingeniería Química, Universidad Autónoma de Madrid, 28049 Madrid, Spain; ๑ orcid.org/0000-0001-5107-7751

Daniel Moreno - Departamento de Ingeniería Química, Universidad Autónoma de Madrid, 28049 Madrid, Spain; (-) orcid.org/0000-0001-9197-9936

José Palomar - Departamento de Ingeniería Química, Universidad Autónoma de Madrid, 28049 Madrid, Spain; ○ orcid.org/0000-0003-4304-0515

Julián García - Departamento de Ingeniería Química y de Materiales, Universidad Complutense de Madrid, 28040

Madrid, Spain; @ orcid.org/0000-0003-1386-4003

Francisco Rodríguez - Departamento de Ingeniería Química y de Materiales, Universidad Complutense de Madrid, 28040 Madrid, Spain

Complete contact information is available at:

https://pubs.acs.org/10.1021/acs.iecr.1c04363

\section{Funding}

The authors are grateful to Comunidad de Madrid (project P2018/EMT4348) and Ministerio de Economia y Competitividad (MINECO) of Spain (projects CTQ2017-85340, CTQ2017-89441-R, and PID2020-118259RB-I00) for its financial support and Centro de Computación Cientifica de la Universidad Autónoma de Madrid(CCC) for its computational resources. Miguel Ayuso also thanks Ministerio de Ciencia Innovación y Universidades for awarding him an FPI grant (PRE2018-083728).

\section{Notes}

The authors declare no competing financial interest.

\section{REFERENCES}

(1) Gary, J. H.; Handwerk, G. E. Petroleum Refining: Technology and Economics; 4th ed.; Marcel Dekker: New York, 2001.

(2) Franck, H. G.; Stadelhofer, J. W. Industrial Aromatic Chemistry; Springer-Verlag: Berlin, 1988.

(3) Canales, R. I.; Brennecke, J. F. Comparison of Ionic Liquids to Conventional Organic Solvents for Extraction of Aromatics from Aliphatics. J. Chem. Eng. Data 2016, 61, 1685-1699.

(4) Rogers, R. D.; Seddon, K. R. Ionic liquids-solvents of the future? Science 2003, 302, 792-793.

(5) Larriba, M.; Navarro, P.; González, E. J.; García, J.; Rodríguez, F. Separation of BTEX from a naphtha feed to ethylene crackers using a binary mixture of $[4 \mathrm{empy}][\mathrm{Tf} 2 \mathrm{~N}]$ and $[\mathrm{emim}][\mathrm{DCA}]$ ionic liquids. Sep. Purif. Technol. 2015, 144, 54-62.

(6) Larriba, M.; Navarro, P.; González, E. J.; García, J.; Rodríguez, F. Dearomatization of pyrolysis gasolines from mild and severe cracking by liquid-liquid extraction using a binary mixture of [4empy][Tf2N] and [emim] [DCA] ionic liquids. Fuel Process. Technol. 2015, 137, 269282.

(7) Greer, A. J.; Jacquemin, J.; Hardacre, C. Industrial Applications of Ionic Liquids. Molecules 2020, 25, 5207.
(8) Werner, S.; Haumann, M.; Wasserscheid, P. Ionic liquids in chemical engineering. Annu. Rev. Chem. Biomol. Eng. 2010, 1, 203-230.

(9) Plechkova, N. V.; Seddon, K. R. Applications of ionic liquids in the chemical industry. Chem. Soc. Rev. 2008, 37, 123-150.

(10) Ji, Y.; Hou, Y.; Ren, S.; Yao, C.; Wu, W. Highly efficient extraction of phenolic compounds from oil mixtures by trimethylaminebased dicationic ionic liquids via forming deep eutectic solvents. Fuel Process. Technol. 2018, 171, 183-191.

(11) Yabushita, M.; Papa, G.; Li, P.; Fukuoka, A.; Farha, O. K.; Simmons, B. A.; Katz, A. Effect of ionic liquid on sugar-aromatic separation selectivity by metal-organic framework NU-1000 in aqueous solution. Fuel Process. Technol. 2020, 197, No. 106189.

(12) Saha, B.; Vedachalam, S.; Dalai, A. K. Review on recent advances in adsorptive desulfurization. Fuel Process. Technol. 2021, 214, No. 106685.

(13) Tullo, A. The time is now for ionic liquids. Chem. Eng. News 98 , 2020, https://cen.acs.org/materials/ionic-liquids/time-ionic-liquids/ 98/i5.

(14) McCoy, M. Chevron Embraces Ionic Liquids. Chem. Eng. News 93, 2016, https://cen.acs.org/articles/94/i39/Chevron-embracesionic-liquids.html.

(15) Tullo, A. Oil Company begins major new use of ionic liquids. Chem. Eng. News. 2021, https://cen.acs.org/materials/ionic-liquids/ Oil-company-begins-major-new/99/web/2021/04.

(16) Larriba, M.; Navarro, P.; Delgado-Mellado, N.; González, C.; García, J.; Rodríguez, F. Dearomatization of Pyrolysis Gasoline with an Ionic Liquid Mixture: Experimental Study and Process Simulation. AIChE J. 2017, 63, 4054-4065.

(17) Larriba, M.; Navarro, P.; Delgado-Mellado, N.; Stanisci, V.; García, J.; Rodríguez, F. Extraction of aromatic hydrocarbons from pyrolysis gasoline using tetrathiocyanatocobaltate-based ionic liquids: Experimental study and simulation. Fuel Process. Technol. 2017, 159, 96-110.

(18) Larriba, M.; Navarro, P.; García, J.; Rodríguez, F. Liquid-liquid extraction of BTEX from reformer gasoline using binary mixtures of $[4 \mathrm{empy}][\mathrm{Tf} 2 \mathrm{~N}]$ and $[\mathrm{emim}][\mathrm{DCA}]$ ionic liquids. Energy Fuels 2014, $28,6666-6676$.

(19) Meindersma, G. W.; Hansmeier, A. R.; De Haan, A. B. Ionic liquids for aromatics extraction. Present status and future outlook. Ind. Eng. Chem. Res. 2010, 49, 7530-7540.

(20) Domínguez, I.; González, E. J.; Domínguez, Á. Liquid extraction of aromatic/cyclic aliphatic hydrocarbon mixtures using ionic liquids as solvent: Literature review and new experimental LLE data. Fuel Process. Technol. 2014, 125, 207-216.

(21) Wilfred, C. D.; Kiat, C. F.; Man, Z.; Bustam, M. A.; Mutalib, M. I. M.; Phak, C. Z. Extraction of dibenzothiophene from dodecane using ionic liquids. Fuel Process. Technol. 2012, 93, 85-89.

(22) Navarro, P.; de Dios-García, I.; Larriba, M.; Delgado-Mellado, N.; Ayuso, M.; Moreno, D.; Palomar, J.; García, J.; Rodríguez, F. Dearomatization of pyrolysis gasoline by extractive distillation with 1ethyl-3-methylimidazolium tricyanomethanide. Fuel Process. Technol. 2019, 195, No. 106156.

(23) Lei, Y.; Zhou, Y.; Wei, Z.; Chen, Y.; Guo, F.; Yan, W. Optimal design of an ionic liquid (IL)-based aromatic extractive distillation process involving energy and economic evaluation. Ind. Eng. Chem. Res. 2021, 60, 3605-3616.

(24) Gutiérrez, J. P.; Meindersma, G. W.; De Haan, A. B. COSMORS-based ionic-liquid selection for extractive distillation processes. Ind. Eng. Chem. Res. 2012, 51, 11518-11529.

(25) Meindersma, W.; Onink, F.; Hansmeier, A. R.; de Haan, A. B. Long Term Pilot Plant Experience on Aromatics Extraction with Ionic Liquids. Sep. Sci. Technol. 2012, 47, 337-345.

(26) Kossack, S.; Kraemer, K.; Gani, R.; Marquardt, W. A systematic synthesis framework for extractive distillation processes. Chem. Eng. Res. Des. 2008, 86, 781-792.

(27) Navarro, P.; Larriba, M.; Delgado-Mellado, N.; Ayuso, M.; Romero, M.; García, J.; Rodríguez, F. Experimental screening towards developing ionic liquid-based extractive distillation in the dearomatization of refinery streams. Sep. Purif. Technol. 2018, 201, 268. 
(28) Navarro, P.; Ayuso, M.; Palma, A. M.; Larriba, M.; DelgadoMellado, N.; García, J.; Rodríguez, F.; Coutinho, J. A. P.; Carvalho, P. J. Toluene/n -Heptane Separation by Extractive Distillation with Tricyanomethanide-Based Ionic Liquids: Experimental and CPA EoS Modeling. Ind. Eng. Chem. Res. 2018, 57, 14242.

(29) Ayuso, M.; Navarro, P.; Palma, A. M.; Larriba, M.; DelgadoMellado, N.; García, J.; Rodríguez, F.; Coutinho, J. A. P.; Carvalho, P. J. Toward Modeling the Aromatic/Aliphatic Separation by Extractive Distillation with Tricyanomethanide-Based Ionic Liquids Using CPA EoS. Ind. Eng. Chem. Res. 2019, 58, 19681.

(30) Ayuso, M.; Palma, A. M.; Larriba, M.; Delgado-Mellado, N.; García, J.; Rodríguez, F.; Coutinho, J. A. P.; Carvalho, P. J.; Navarro, P. Experimental and CPA EoS Description of the Key Components in the BTX Separation from Gasolines by Extractive Distillation with Tricyanomethanide-Based Ionic Liquids. Ind. Eng. Chem. Res. 2020, 59, 15058-15068.

(31) Larriba, M.; de Riva, J.; Navarro, P.; Moreno, D.; DelgadoMellado, N.; García, J.; Ferro, V. R.; Rodríguez, F.; Palomar, J. COSMO-based/Aspen Plus process simulation of the aromatic extraction from pyrolysis gasoline using the $\{[4 \mathrm{empy}][$ NTf 2$]+$ $[\mathrm{emim}][\mathrm{DCA}]\}$ ionic liquid mixture. Sep. Purif. Technol. 2018, 190, 211-227.

(32) Ferro, V. R.; Moya, C.; Moreno, D.; Santiago, R.; De Riva, J.; Pedrosa, G.; Larriba, M.; Diaz, I.; Palomar, J. Enterprise Ionic Liquids Database (ILUAM) for Use in Aspen ONE Programs Suite with COSMO-Based Property Methods. Ind. Eng. Chem. Res. 2018, 57, 980989.

(33) Thyssenkrupp. World Market Leader in Aromatics Extraction, 2014.

(34) De Riva, J.; Ferro, V. R.; Moreno, D.; Diaz, I.; Palomar, J. Aspen Plus supported conceptual design of the aromatic - aliphatic separation from low aromatic content naphtha using 4-methyl-N-butylpyridinium tetra fl uoroborate ionic liquid. Fuel Process. Technol. 2016, 146, 29-38.

(35) Ferro, V. R.; de Riva, J.; Sanchez, D.; Ruiz, E.; Palomar, J. Conceptual design of unit operations to separate aromatic hydrocarbons from naphtha using ionic liquids. COSMO-based process simulations with multi-component "real" mixture feed. Chem. Eng. Res. Des. 2015, 94, 632-647.

(36) Hernández, E.; Santiago, R.; Moya, C.; Navarro, P.; Palomar, J. Multiscale evaluation of $\mathrm{CO} 2$-derived cyclic carbonates to separate hydrocarbons: Drafting new competitive processes. Fuel Process. Technol. 2021, 212, No. 106639.

(37) Larriba, M.; Navarro, P.; Delgado-Mellado, N.; Stanisci, V.; García, J.; Rodríguez, F. Separation of aromatics from n-alkanes using tricyanomethanide-based ionic liquids: Liquid-liquid extraction, vaporliquid separation, and thermophysical characterization. J. Mol. Liq. 2016, 223, 880-889.

(38) Navarro, P.; Moreno, D.; Álvarez, J.; Santiago, R.; HospitalBenito, D.; Ferro, V. R.; Palomar, J. Stripping Columns to Regenerate Ionic Liquids and Selectively Recover Hydrocarbons Avoiding Vacuum Conditions. Ind. Eng. Chem. Res. 2019, 20370.

(39) Jongmans, M. T. G.; Trampé, J.; Schuur, B.; de Haan, A. B. Solute recovery from ionic liquids: A conceptual design study for recovery of styrene monomer from [4-mebupy][BF4]. Chem. Eng. Process. Process Intensif. 2013, 70, 148-161.

(40) Chan, H.; Fair, J. R. Prediction of Point Efficiencies on Sieve Trays. 1. Binary Systems. Ind. Eng. Chem. Process Des. Dev. 1984, 23, 814-819.

(41) Navarro, P.; Larriba, M.; Rojo, E.; García, J.; Rodríguez, F. Thermal properties of cyano-based ionic liquids. J. Chem. Eng. Data 2013, 58, 2187-2193.

(42) Navarro, P.; Larriba, M.; García, J.; Rodríguez, F. Thermal stability and specific heats of $\{[\mathrm{emim}][\mathrm{DCA}]+[\mathrm{emim}][\mathrm{TCM}]\}$ mixed ionic liquids. Thermochim. Acta 2014, 588, 22-27.

(43) Mulyono, S.; Hizaddin, H. F.; Alnashef, I. M.; Hashim, M. A.; Fakeeha, A. H.; Hadj-Kali, M. K. Separation of BTEX aromatics from noctane using a (tetrabutylammonium bromide + sulfolane) deep eutectic solvent-experiments and COSMO-RS prediction. RSC Adv. 2014, 4, 17597-17606.
(44) Brondani, L. B.; Flores, G. B.; Soares, R. P. Modeling and simulation of a benzene recovery process by extractive distillation, Brazilian. J. Chem. Eng. 2015, 32, 283-291.

(45) Kolbe, B.; Wenzel, S. Novel distillation concepts using one-shell columns. Chem. Eng. Process. 2004, 43, 339-346.

(46) Diehl, T.; Kolbe, B.; Gehrke, H. Separations: Recovering pure aromatics. Pet. Technol. Q. 2006, 11, 127-131.

(47) Emmrich, G.; Gehrke, H.; Ranke, U. Working with an extractive distillation process. Pet. Technol. Q. 2001, 6, 125-129.

(48) Towler, G.; Sinnot, R. Chemical Engineering Desing: Principles, Practice and Economics of Plant and Process Deisng, 2nd ed.; ButterworthHeinemann, 2012.

(49) Wang, Q.; Chen, J. Y.; Pan, M.; He, C.; He, C. C.; Zhang, B. J.; Chen, Q. L. A new sulfolane aromatic extractive distillation process and optimization for better energy utilization. Chem. Eng. Process. 2018, 128, $80-95$.

(50) Seader, J. D.; Henley, E. J.; Roper, D. K. Separation Process Principles, 3rd ed.; John Wiley \& Sons, 2009.

(51) Kontogeorgis, G. M.; Michelsen, M. L.; Folas, G. K.; Derawi, S.; Von Solms, N.; Stenby, E. H. Ten Years with the CPA (Cubic-PlusAssociation) equation of state. Part 1 . Pure compounds and selfassociating systems. Ind. Eng. Chem. Res. 2006, 45, 4855-4868.

(52) Kontogeorgis, G. M.; Michelsen, M. L.; Folas, G. K.; Derawi, S.; Von Solms, N.; Stenby, E. H. Ten Years with the CPA (Cubic-PlusAssociation) equation of state. Part 2. Cross-associating and multicomponent systems. Ind. Eng. Chem. Res. 2006, 45, 4869-4878.

(53) Ayuso, M.; Navarro, P.; Palma, A. M.; Larriba, M.; DelgadoMellado, N.; García, J.; Rodríguez, F.; Coutinho, J. A. P.; Carvalho, P. J. Separation of benzene from methylcycloalkanes by extractive distillation with cyano-based ionic liquids: Experimental and CPA EoS modelling. Sep. Purif. Technol. 2020, 234, No. 116128.

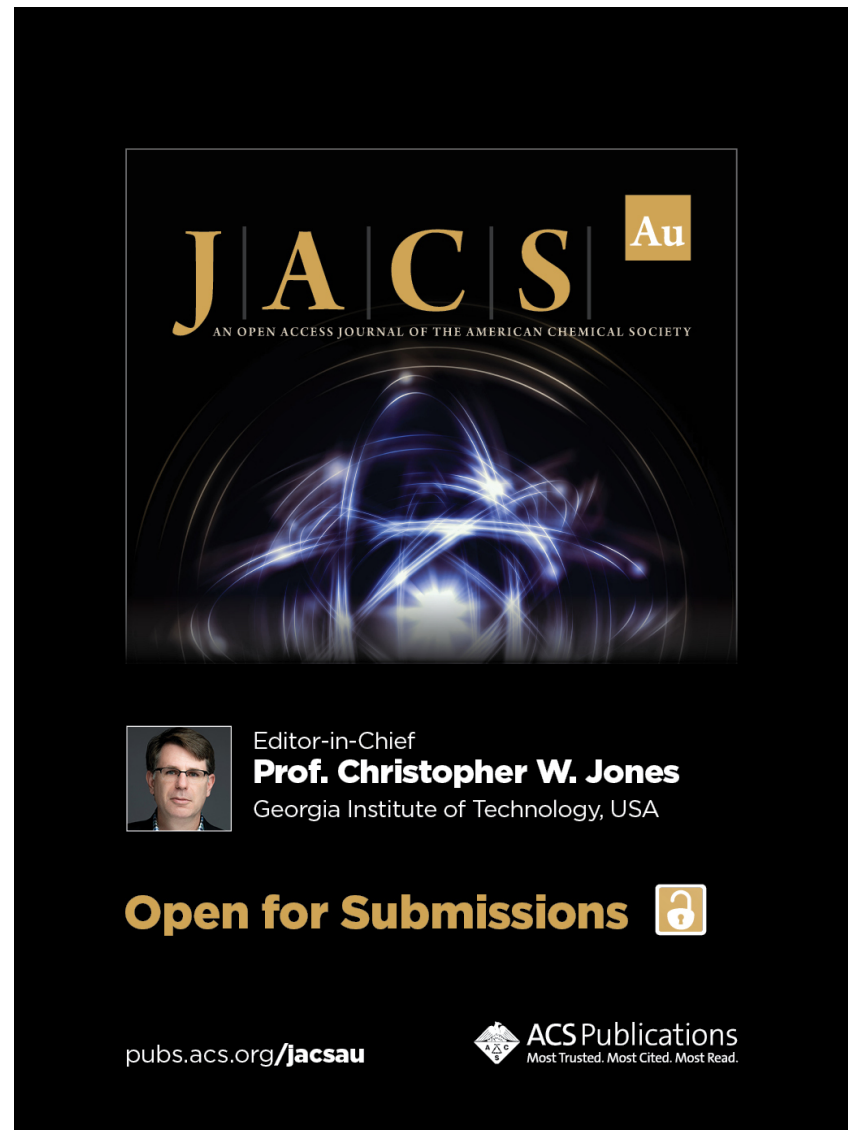

